
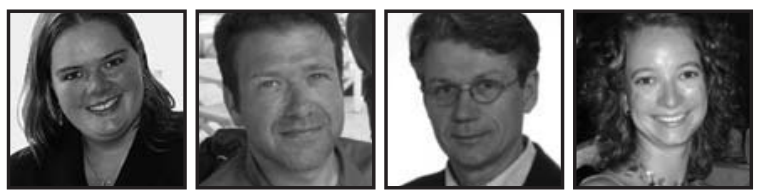

\title{
School Bonding: Helping At-Risk Youth Become Students At-Promise
}

\author{
Anne Lessard, Éric Yergeau, Laurier Fortin \& Martine Poirier \\ Université de Sherbrooke
}

\section{ABSTRACT}

The purpose of this study was to determine if non at-risk and four types of at-risk secondary school students perceive school bonding differently. Findings indicate there are differences between the two groups of students on affective, cognitive and behavioral components of school bonding, although no differences were found between at-risk types. Girls showed stronger bonds to school while boys who were depressed were less affiliated to peers and fostered more negative attitudes towards teachers than other students.

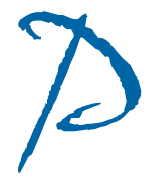

romoting students' achievement and graduation and preventing school dropout have been established as important goals in a number of studies in education in the past decade (Rumberger, 1995).

Researchers studying school dropout have focused on identifying aspects of schooling which contribute to the probability that a student will leave school prematurely (risk factors) while others have identified protective factors which contribute to increasing the likelihood that a student will persevere and succeed in obtaining a diploma. The evidence suggests that not all personal, family-related or school-related factors influence all students in a similar fashion (Fortin, Royer, Potvin, Marcotte \& Yergeau, 2004); however, when a student displays several risk factors, the student is then considered at-risk. When attempting to prevent school dropout and increase graduation rates, educators generally focus on school factors as those seem to be the best means to help turn the tide for students from an at-risk to an at-promise status (Sanders, 2000). 
Although there are several school-related factors present in the literature on school dropout (Fortin et al., 2004; Garnier, Stein \& Jacobs, 1997; Rumberger, 1995), school bonding has been found to be a significant protective factor that helps eliminate dropout (Hawkins, Guo, Hill, Battin-Pearson \& Abbott, 2001; Simons-Morton, Crump, Haynie \& Saylor, 1999). Theoretical models have positioned school bonding as contributing to the risk level (Battin-Pearson et al., 2000; Tinto, 1987) and the academic developmental trajectories of students (Finn, 1989) or as a predictor of the outcome of either graduation or dropout. In this article the concept of school bonding will be defined; studies focusing on school bonding in at-risk students will then be presented, along with different profiles of at-risk students.

Maddox and Prinz (2003) and Libbey (2004) reviewed the literature to consolidate the theoretical models that define school bonding. Researchers generally rely on one of two models that define school bonding, namely Hirschi's (1969) control theory or Catalano and Hawkins' (1996) social development model (Maddox \& Prinz, 2003). Both models include attachment (close affective relationships) and commitment (investment in school and doing well) as two defining elements of school bonding.

In her critical review of the literature on school bonding, Libbey (2004) found nine constructs present in most studies aimed at assessing the bond students establish with school. The five most prevalent were teacher support, academic/student engagement, peer support/affiliation, general appreciation of school and discipline/fairness. School bonding thus represents a comprehensive concept involving affective (attachment), cognitive (commitment) and behavioral (involvement) components.

Although some studies have focused on the elements that make up the three basic constructs of school bonding, such as involvement measured through student engagement (Caraway, Tucker, Reinke \& Hall, 2003; Furrer \& Skinner, 2003), or attachment as viewed through teacher support (Klem \& Connell, 2004; Patrick, Ryan \& Kaplan, 2007), or peer support (Patrick, Ryan \& Kaplan, 2007), few have focused specifically on the influence of school bonding on school outcomes in at-risk students. Those researchers who did often focused on one dimension of school bonding such as commitment (Finn \& Rock, 1997) or attachment measured through the studentteacher relationship (Baker, 2006; Fortin et al., 2004; Janosz \& Fallu, 2003; Lessard, Fortin, Joly, Royer \& Blaya, 2004) or through peer affiliation/support (Battin-Pearson et al., 2000; Murdock, 1999). Findings from these studies indicate that positive commitment and attachment to both teachers and peers tend to decrease the dropout risk. 
Catalano's and Hawkins' research groups are among the few to report significant results on school bonding with at-risk and non at-risk students (Catalano, Haggerty, Oesterle, Fleming \& Hawkins, 2004; Hawkins et al., 2001). Findings from the Seattle Social Development and the Raising Healthy Children research projects, which followed respectively 808 students from first grade to 27 years of age and 938 students over the course of 12 years, indicate theoretical and empirical support for school bonding. They suggest it is a critical element in the developmental trajectories of students. Results show that in addition to increasing academic achievement and social competence, strong school bonding contributes to decreasing school dropout (Catalano et al., 2004).

In a longitudinal study focusing on the academic achievement and social adaptation of 810 secondary school students (54\% males; $46 \%$ females) using repeated measures evaluating personal, family and school-related risk factors, Fortin, Marcotte, Potvin, Royer and Joly (2006) identified four types of students placed at risk for school dropout. Their clustering analysis enabled them to categorize these types as: 1 ) the Antisocial Covert Behavior type; 2) the Uninterested in School type; 3) the School and Social Adjustment Difficulties type and 4) the Depressive type of at-risk students. All four types share some common characteristics: they show significantly higher levels of depression, report lower scores on both parental emotional support and family organization and perceive less order and organization in the classroom than do other students.

Beyond these characteristics, the factors which place the Antisocial Covert Behavior students at risk are their covert antisocial behaviors (stealing and cheating, for example) and their low levels of family cohesion and parental control. The Uninterested in School type of student is the largest group and the one which most resembles non at-risk students. They perform well in school, are well liked by their teachers but lack motivation towards schoolwork. Students with School and Social Adjustment Difficulties compose the second most important group and the one which presents the greatest challenge for educators as they show high levels of depression and delinquency and display both high levels of behavior problems and the lowest academic achievement levels of all students. Finally, beyond their high scores on the depression scale, with $42 \%$ reporting suicidal thoughts, the Depressive type of student shows the most negative scores on all family functioning scales.

Few studies have focused on school bonding in at-risk students although research indicates that low school bonding contributes to increasing the potential for dropout (Battin-Pearson et al., 2000; Catalano et al., 2004). Thus, it seems important to 
study school bonding in secondary school students while paying attention to the different profiles of at-risk students. Considering the constructs defining school bonding and the specific vulnerabilities of middle school students (Baker, 2006), the purpose of this study was to investigate if there is a difference between at-risk and non at-risk middle school students on school bonding as defined by attachment (teacher support, peer support/affiliation), commitment (students' perception of rules and their attitudes towards school) and involvement (student engagement).

\section{Methodology}

In order to reach the research objectives, 715 8th grade students (349 boys and 366 girls) from the Eastern Townships in the province of Quebec were asked and consented to participate in this study. The students who were recruited were 14 years old on average and attended six different urban schools that were considered underprivileged.

Beyond academic achievement in mathematics, and either French or English (depending on the language of instruction) obtained from the schools, students provided answered to six questionnaires chosen on the basis of their psychometric properties (Fortin et al.'s, 2006). These tools were used to identify at-risk students and to place them in one of the four at-risk types. The tool used to evaluate the dropout risk was Decisions (Quirouette, 1988). Composed of 39 questions, this questionnaire covers six dimensions: family environment, personal characteristics, school plans, academic abilities, student-teacher relationship and school motivation. The Family Assessment Device (FAD, Epstein, Connors and Salinas, 1983) is composed of 60 questions measuring the social and environmental characteristics of the family. As this is a self-reported tool, it evaluates the student's perception of how his/her family is functioning. The Classroom Environmental Scale (CES, Moos and Tricket, 1987) measures the classroom social climate and school bonding with scales focusing on student commitment, affiliation to peers, perceived teacher support, order and organization in the classroom, appropriateness of tasks, competition with peers, understanding of the rules and teacher control and innovation. Each scale consists of five statements to which the student responds either "true" or "false." The Child Behavior Checklist (CBCL, Achenbach, 1991) evaluates externalized (aggressive behavior and delinquency) and internalized (anxiety, depression, withdrawal) behavior problems. For each of the 113 questions, the student chooses an answer on a three-point Likert-type scale. The Behavior Assessment System for Children (BASC, Reynolds \& Kamphaus, 1992) measures 
the student's behavior using 130 questions composing 12 scales. In the context of this study, two scales were used, namely, the student's attitude towards the teacher and his or her attitude towards the school. The scales represent a total of 19 questions to which the student answers by "true" or "false." Finally, the Beck Depression Index (BDI, Beck, 1978) is composed of 21 statements assessing the intensity of emotional, behavioral, cognitive and somatic symptoms characteristic of depression. For each statement, the student selects an answer from a choice of four, from 0 to 3.

School bonding was assessed using the combination of five scales from the CES (Moos \& Tricket, 1987) and two attitude scales found in the BASC (Reynolds and Kamphaus, 1992) which Maddox and Prinz (2003) deemed appropriate for measuring attachment and commitment.

After having been informed of the purpose of the study by the school principal, students received the written description of the research project and the consent form to be signed by willing participants and their parents. The students who agreed to participate answered the questionnaires in their classrooms, during a 90minute period of class time, supervised by trained research assistants. Data collection occurred during the spring of 2002.

\section{Findings}

In order to attain research objectives, the first step was to determine the number of at-risk students and to assess to which type they belonged. The results of the scores obtained on the Decisions (Quirouette, 1988) measure of dropout risk, indicated that 134 boys (38.4\%) and $136(37.2 \%)$ girls were considered at-risk while 215 boys and 230 girls were not. Forty-six students ( 21 boys, 25 girls) belonged to the Antisocial Covert Behavior type, 57 (41 boys, 16 girls) were Uninterested in School, 128 (58 boys, 70 girls) had School and Social Adjustment Difficulties and 39 (14 boys, 25 girls) were Depressive.

In order to determine whether there were differences in the students' perception of school bonding, researchers assessed gender and the four at-risk types against all the school bonding scales described earlier (multivariate analysis of covariance). Age and academic achievement were included in the process because of their potential confounding effects. 
The results indicate that there were highly significant group and gender effects as well as a smaller but still significant group and gender interaction effect on the school bonding constructs. At-risk and non at-risk students show significant differences across all measures of school bonding with attitudes toward teachers and school being the two elements with the highest influence. Results suggest that all four at-risk types show significantly less favorable scores on attachment, commitment and involvement than the non at-risk group. Further analysis (discriminant analysis) performed with only the at-risk types allowed researchers to investigate the ways in which the four types differ one from another. Findings indicate that while atrisk students are all consistently different from the non at-risk students, there are no differences between students belonging to the four at-risk types.

When gender was considered (univariate analysis for gender effect), findings indicate that overall, girls reported better bonding to school than boys, specifically in terms of engagement, affiliation, clarity of rules, and general attitude toward teachers and school. When considering both gender and types of students in the analysis (univariate tests), only two elements were found to be of some significance, namely affiliation and the attitude toward teacher. Globally, boys belonging to the Depressive type report fewer affiliations with peers and a more negative attitude towards teachers than other students.

\section{Discussion}

Two trends stem from the results of this study. First, there is a significant difference between the four at-risk types and non at-risk students on all measures of school bonding, with at-risk students obtaining more negative scores than their classmates. At-risk students foster more negative attitudes towards both their teachers and school, they are less affiliated to their peers and show lower levels of engagement in school than do non at-risk students. Little research has taken place to date to assess the influence of school bonding on school outcomes in at-risk students. The researchers who have assessed this influence have reported significant differences between at-risk and non at-risk students (Baker, 2006; Catalano et al., 2004, Fortin et al., 2004, Lessard et al., 2004). However, each of these studies investigated one particular type of student or one specific construct linked with school bonding, as opposed to several school bonding measures for different types of students. Baker (2006) documented school bonding with primary school students displaying behavior problems or learning difficulties. Catalano et al. (2004) focused on behavior problems. 
Fortin et al. (2004) and Lessard et al. (2004) reported results on teacher-student relationships with at-risk secondary school students. As at-risk students have long been categorized as displaying either behavior problems or learning difficulties, it follows that little is known to date on school bonding as it pertains to the other types of atrisk students, such as students who are uninterested in school or who are depressed.

The second trend relates to gender. Generally, girls fared better than boys on most school bonding measures, a finding which was anticipated and confirms previous research (Baker, 2006; Furrer \& Skinner, 2003; Simons-Morton et al., 1999). An interesting finding among the boys belonging to the Depressive type: was that they are less affiliated to peers and show more negative attitudes towards teachers than do other students. As none of the work on school bonding included the influence of depression in their research, our findings relating to depressive boys are unprecedented in this field of study. However, in studying internalized behavior problems in middle school students, Marcotte, Cournoyer, Gagné and Bélanger (2005) documented the lack of affiliation to peers in depressive boys, which they attributed to the poor social skills they had. The researchers suggested that this trend should be investigated further. In terms of depressive boys' relationships with teachers, results from a previous study show that boys who perceive their relationship with teachers as negative are placed at greater risk of dropping out of school than other students (Lessard et al., 2004). Male dropouts also talk about the conflicts with teachers which contributed to their decision to leave school prematurely (Lessard et al., in press). This evidence suggests that boys may be more sensitive to the affective aspect of the bonds they establish with peers and teachers and may, in turn, modify their behavior in a response to the lack of perceived affective support.

These two trends have some important implications for teachers. As was stated earlier the affective, cognitive and behavioral components of school bonding are involved in promoting the bond that students build and maintain with the school and more specifically with teachers and peers. Knowing that students with specific characteristics may experience a greater challenge in becoming and remaining engaged in school, educators need to identify these students and to structure educational activities aimed at increasing their bond to school and decreasing the probability that they will leave school before graduating. Although it could be argued that focusing on the student's deficits only increases the negative perception which some attribute to at-risk students, it could equally be argued that assessing the student's risk status may provide educators with a means to identify who may or may not require more help. Knowing that the support a teacher offers his or her students contributes to enhancing the bond to school through an affective element, teachers 
should be more aware of the quality of the relationships they establish with students as it also affects both the cognitive development and the behavioral outcomes of students. In essence, teachers can contribute to changing the students' own perceptions of whether they are at-risk or whether they can be considered at-promise. Knowing that the students' attitudes towards the teacher and the school are the two elements which seem to have the greatest influence on the level of school bonding, efforts should be devoted to providing students with contexts in which they feel supported and cared for. This would help them have more positive self perceptions as students and thus increase their bond to school.

This study has limitations. The results were obtained using self-reported measures and did not take into account other perspectives, such as those of educators which could have provided a more rounded understanding of school bonding. Interviews with students, teachers and administrators could have provided a more contextualized picture of school bonding in middle school students.

\section{Conclusion}

This study on school bonding in middle school students compared four at-risk types of students to their classmates on attachment, commitment and involvement. All four at-risk types presented significantly more negative scores on all measures than did other students. Girls reported being more engaged and better affiliated with their peers, perceiving rules as clearer and displaying better attitudes towards both the teachers and the school than did boys. Boys belonging to the Depressive type of students showed lower attachment (less affiliated to peers and fostered more negative attitudes towards teachers) than did other students. Finally, the innovative contribution of this study highlights the importance that students attribute to their bond to school and, more particularly, to their relationships with teachers and their general attitude towards school.

In attempting to find effective avenues to increase student perseverance and achievement, this study contributes findings which highlight the need for intervention on two specific targets. First, as was stated by Finn and Rock (1997), school bonding and, more specifically, student engagement may act as protective factors and could therefore be reinforced by school personnel, especially for students who are placed at risk of dropping out of school. Second, boys belonging to the Depressive type seem to be particularly vulnerable to the lack of positive support 
from teachers and interactions with peers. Helping these students establish better social skills may contribute to increasing their attachment to school and consequently decreasing their dropout risk level.

Changing the lens through which students are perceived from at-risk youth to students at-promise, looking at the students' strengths and working with them to alleviate their obstacles to success represents an important challenge which, if successfully achieved by school personnel, could contribute to changing the educational trajectories of a large group of students.

\section{References}

Achenbach, T. (1991). Child behavior checklist: Manual for the teacher's report form and profile. Burlington, VT, University of Vermont.

Baker, J. (2006). Contributions of teacher-child relationships to positive school adjustment during elementary school. Journal of School Psychology, 44, 211-229.

Battin-Pearson, S., Newcomb, M., Abbott, R., Hill, K., Catalano, R., \& Hawkins, J. (2000). Predictors of early high school dropout: A test of five theories. Journal of Educational Psychology, 92, 568-582.

Beck, A. (1978). Depression inventory. Philadelphia, PA: Center for Cognitive Therapy.

Caraway, K., Tucker, C., Reinke, W. \& Hall, C. (2003). Self-efficacy, goal-orientation and fear of failure as predictors of school engagement in high school students. Psychology in the Schools, 40(4), 417-427.

Catalano, R. \& Hawkins, J. (1996). The social development model: A theory of antisocial behavior. In Hawkins, J., ed. Delinquency and Crime: Current Theories. Cambridge University Press: New York, 149-197.

Catalano, R., Haggerty, K., Oesterle, S., Fleming, C. \& Hawkins, J. (2004). The importance of bonding to school for healthy develop- ment: Findings from the social development research group. Journal of School Health, 74(7), 252-261.

Epstein, J., Connors, L. \& Salinas, K. (1983). High school and family partnerships: Questionnaires for teachers, parents, and students. Baltimore, MD: Johns Hopkins University, Center of Families, Communities, Schools, and Children's Learning.

Finn, J. (1989). Withdrawing from school. Review of Educational Research 59(2), 117-142.

Finn, J. \& Rock, D. (1997). Academic success among students at risk for school failure. Journal of Applied Psychology, 82(2), 221234.

Fortin, L. (2002). Entente spécifique sur la réussite scolaire en Estrie. Sherbrooke, QC: Université de Sherbrooke.

Fortin, L., Marcotte, D., Potvin, P., Royer, E. \& Joly, J. (2006). Typology of student at risk of dropping out of school: Description by personal, family and school factors. European Journal of Psychology of Education, 21(4), 363-383.

Fortin, L., Royer, E., Potvin, P., Marcotte, D. \& Yergeau, E. (2004). La prédiction du risque de décrochage scolaire au secondaire: Facteurs personnels, familiaux et scolaires. Revue canadienne des sciences du comportement, 36(3), 219-231. 
Furrer, C. \& Skinner, E. (2003). Sense of relatedness as a factor in children's academic engagement and performance. Journal of Educational Psychology, 95(1), 148-162.

Garnier, H., Stein, J. \& Jacobs, J. (1997). The process of dropping out of high school: A 19-year perspective. American Educational Research Journal, 34, 395-419.

Hawkins, J., Guo, J., Hill, K., Battin-Pearson, S. \& Abbott, R. (2001). Long-term effects of the Seattle Social Development Intervention on School Bonding Trajectories. Applied Developmental Science, 5(4), 225-236.

Hirschi,T. (1969) Causes of Delinquency. Berkeley, CA: University of California Press.

Janosz, M. \& Fallu, J.-S. (2003). La qualité des relations élève-enseignants à l'adolescence: un facteur de protection de l'échec scolaire. Revue de psychoéducation, 32(1), 7-29.

Klem, A. \& Connell, J. (2004). Relationships matter: Linking teacher support to student engagement and achievement. The Journal of School Health, 74(7), 262-273.

Lessard, A., Fortin, L., Joly, J., Royer, É., \& Blaya, C. (2004). Students at-risk for dropping out of school: Are there gender differences among personal, family and school factors? Journal of At-Risk Issues, 10(2), 91-127.

Lessard, A., Butler-Kisber, L., Fortin, L., Royer, E., Marcotte, D. \& Potvin, P. (in press). Shades of disengagement: High school dropouts speak out. Social Psychology of Education.

Libbey, H. (2004). Measuring student relationship to school: Attachment, bonding, connectedness and engagement. Journal of School Health, 74(7), 274-283.

Maddox, S. \& Prinz, R. (2003). School bonding in children and adolescents: Conceptualization, assessment and associated variables. Clinical Child and Family Psychology Review, 6(1), 31-49.

Marcotte, D., Cournoyer, M., Gagné, M.-Ė. \& Bélanger, M. (2005). Comparaison des facteurs personnels, scolaires et familiaux associés aux troubles intériorisés à la fin du primaire et au début du secondaire. Nouveaux cahiers de la recherche en éducation, 8(2), 57-67.
Ministère de l'Éducation. (2004). Indicateurs de l'éducation. Quebec, QC: Author

Moos, R., \& Tricket, E. (1987). Classroom environment scale manual. Palo Alto, CA: Consulting Psychologists Press.

Murdock, T. (1999). The social context of risk: Status and motivational predictors of alienation in middle school. Journal of Educational Psychology, 91(1), 62-75.

Patrick, H., Ryan, A. \& Kaplan, A. (2007). Early adolescents' perceptions of the classroom social environment, motivational beliefs and engagement. Journal of Educational Psychology, 99(1), 83-98.

Quirouette, P. (1988). Décisions. Orleans, ON: PIOR Recherche en éducation.

Reynolds, C., \& Kamphaus, R. (1992). Behavioral Assessment System for Children Manual. Minneapolis, MN: Circle Times.

Rumberger, R. (1995). Dropping out of middle school: A multilevel analysis of students and schools. American Educational Research Journal, 32, 583-625.

Sanders, M.G. (2000) Schooling Students placed at risk: Research, policy, and practice in the education of poor and minority adolescents. Mahwah, NJ: Lawrence Erlbaun.

Simons-Morton, S., Crump, A., Haynie, D. \& Saylor, K. (1999). Student-school bonding and adolescent problem behavior. Health Education Research, 14(1), 99-107.

Tinto, V. (1987). Leaving college: Rethinking the causes and cures of student attrition. Chicago: University of Chicago Press. 


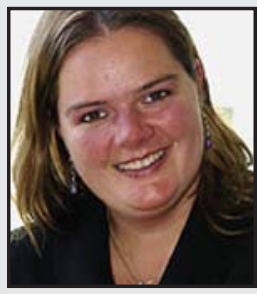

Dr. Anne Lessard is an Associate Professor at the University of Sherbrooke in the Special Education Department of the Faculty of Education. She received her doctorate degree in 2004. Her doctoral work focused on gender differences in high school dropouts. Her research interests also include school bonding, classroom management, student-teacher relationship and students at-risk or having dropped out of school.

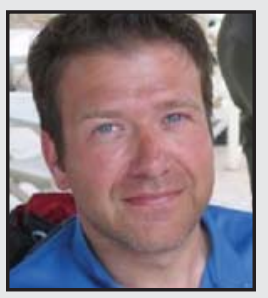

Dr. Éric Yergeau is an Associate Professor at the University of Sherbrooke in the Counselling Department of the Faculty of Education. His work is dedicated in part to the study of the vocational and social trajectories of young adults struggling with adaptation problems.

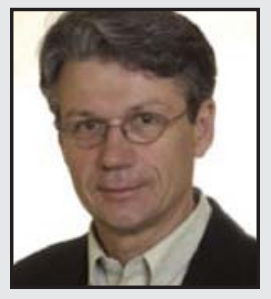

Dr. Laurier Fortin is a Professor at the University of Sherbrooke and the director of the Psychoeducation Department of the Faculty of Education. He has conducted research on school dropouts over the last 25 years and has been awarded the Research Chair on School Achievement and Perseverance (2007-2012) by the Sherbrooke School Board in partnership with the University of Sherbrooke. His research interests also include student engagement, antisocial behaviour and school violence.

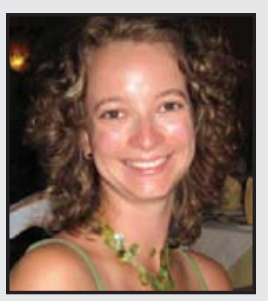

Ms. Martine Poirier graduated from the University of Sherbrooke with her M.A. in Education in 2007. She has since started her doctorate at the Université du Québec à Montréal under the supervision of Dr. Diane Marcotte. Her research interests include student-teacher relationships, internalized behaviour problems and school dropout.

LINK TO:

http://www.usherbrooke.ca/education/personnel/professeur/as/lessardanne.html 